\title{
To What Extent Financial Autonomy Affects Social Security Expenditure
}

\author{
$\mathrm{Hu} \mathrm{Ziyao}^{1, \mathrm{a}^{*}}$ \\ 1 Department of Economics, Beijing University of Posts and Telecommunications, Haidian District, Beijing, China \\ acandybeijing9@163.com
}

\begin{abstract}
Social security expenditure is affected by many factors. According to the ' the flypaper effect ' and public choice theory, it can be concluded that the high financial transfer payment of the superior government will expand the local fiscal expenditure, and the local governments have the motivation to increase fiscal expenditure in order to obtain more transfer payments. However, if different fiscal expenditure items are considered, such as social security expenditure, this effect may change. In this regard, this paper uses fiscal autonomy to express the dependence of local governments on superior transfer payments, and selects panel data from 2009 to 2018 to empirically test the social security expenditure of 31 provinces in China. The results show that fiscal autonomy has a negative impact on social security expenditure, but this impact is not particularly large. The social security expenditure of a province is mainly related to local economic development level, aging degree, unemployment rate and other factors.
\end{abstract}

Keywords: Fiscal autonomy, social security expenditure, the flypaper effect

\section{财政自主权在多大程度上影响了社会保障支出}

\author{
胡紫瑶 $1, a^{*}$
}

1 北京邮电大学经济学系, 海淀区, 北京, 中国

a candybeijing9@163.com

\section{摘要}

社会保障支出受到多种因素的影响。根据 “粘纸效应” 和公共选择理论可以得出，上级政府的高转移支付会使 地方财政支出扩大、且各地政府为获得更多转移支付都有增加财政支出的动机。不过，若分别考虑不同财政支 出项目, 如社会保障支出, 这一影响可能会发生改变。对此, 本文用财政自主权表示地方政府对上级转移支付 的依赖程度，选取 2009-2018 年的面板数据，对我国 31 个省份的社会保障支出进行实证检验。结果表明，财 政自主权对社会保障支出有负向影响，但这一影响并不是特别大。一省的社会保障支出主要还是与当地经济发 展水平、老龄化程度、失业率等因素相关。

关键词: 财政自主权；社会保障支出；粘纸效应

\section{1. 引言}

社会保障制度是通过国民收入的再分配，对公民 在生活发生困难时给予物质帮助、用以保障居民最基 本生活需要的制度, 是现代国家最重要的社会经济制 度之一。随着经济的不断发展, 公共服务与社会保障 越来越被人们所关注。

与此相联系，政府的社会保障支出是提供公共服
务与生活保障的一种形式, 也是衡量政府社会福利投 入的一项指标, 在整个财政支出体系中有重要地位。 从以往研究结论看, 社会保障支出水平受到多种因素 的影响。不仅包括财政收入绝对额、经济发展水平、 老龄化程度、失业率等因素, 还与财政收入结构有关。 而一地的财政收入结构可以用地方财政自主权来表 示。它是指，地方政府的支出在多大程度上依赖于自 有收入 (而非上级转移支付)，这一指标越高，说明一 
地支出更多地依赖本级财政收入。

根据 “粘纸效应” 和公共选择理论, 一地财政自 主权越低, 则地方财政支出越多。但这一影响只是对 财政支出总量上而言, 并未考虑财政支出各项的特殊 性。若将财政支出分项来看, 考虑到社会保障支出对 于社会来说属于 “刚性需求”, 难以短时期内大幅变 动, 财政自主权对其的影响也就有可能会发生改变。 因此, 本文选取了 2009-2018 年的面板数据, 对我国 31 个省份的社会保障支出进行实证检验, 考察财政自 主权对地方社保支出的影响程度, 并得出一些结论。

本文第二部分是文献综述, 第三部分说明变量、 模型与数据, 第四部分对实证结果进行分析, 最后得 出结论, 并提出政策建议。

\section{2. 文献综述}

公共选择理论认为, 政府官员追求的目标是预算 最大化, 这导致地方政府在获得转移支付后, 其预算 加速膨胀, 制造出过多的公共服务, 公共支出规模随 之持续扩大 (即粘纸效应中的垄断性政府假说)。虽 然我国地方政府的财政预算须人民代表大会审议通 过, 但最终结构依旧会受地方政府追求高预算这一行 为的影响。同时，在代议制下，政府决策受政治家、 官僚、利益集团、选民的共同影响。这其中, 代替公 众行使权力的是政治家与政府官员，他们为了自身利 益考虑, 并不会全心全意考虑公共利益; 再加上给地 方政府的财政拨款会受其上年财政支出的影响, 为保 证下年获得的转移支付不减少, 尽力花掉本年获得的 转移支付则成了地方政府的选择。

对于一些财政支出主要依靠中央拨款而非本级 税收的省份来说, 每年能够支出的金额并不掌握在自 己手中, 因此它们会更加有动机扩大支出水平, 尽力 花费中央拨款，使得自己来年能获得更多的转移支付。

关于影响地方政府支出规模的问题, 早期学者认 为影响政府规模的主要因素是财政收入约束, 而收入 的结构并没有影响。即地方政府将转移支付与本地税 收都作为财政收入等同看待, 政府规模不会因为财政 收入结构发生变化 (Bradford and Otaes, 1971)。 然而, 实证研究却发现在相同财政收入的地方, 转移 支付比重更高的地方的政府规模越大 (Hines and Thaler，1995)，这一的现象被称为粘纸效应。

在我国，随着 1994 年分税制的实施，财权大幅 度集中于中央政府, 中央本级财政收入占总财政收入 的比重从 1993 年的 $22 \%$ 上升到 2006 年的 $52.8 \%$ 。 与此同时，支出责任依然由地方政府承担，因而每年 中央政府都会将大量的财政资源转移给地方政府, 净 转移支付从 1994 年的 1819 亿元增加到 2006 年 的 12714 亿元。而地方政府财政支出在分税制改革 后也逐年增长, 这很有可能与 “粘纸效应” 的影响有 关。范子英和张军 (2010) 使用分税制改革以来的省 级面板数据进行研究后证明了这一观点, 认为转移支
付在中国存在 “粘纸效应”, 是促使地方政府支出增 长的重要因素。

同时，对于国外经典文献提出的解释粘纸效应的 四种假说，即财政幻觉假说、垄断性政府假说、压力 集团假说和税收成本假说，毛捷、吕冰洋、马光荣 （2010）通过引入 “价格效应”-——转移支付导致公 共服务的价格下降，说明 “价格效应” 是转移支付促 使地方政府支出较快增长的关键因素, 印证了税收成 本假说（即政府通过征税筹集提供各类公共服务所需 的资金，会造成无谓损失。如果以转移支付作为资金 来源, 可降低甚至消除征税的筹资成本。因此, 当资 金更多地来自于转移支付时，地方政府会选择较高的 支出水平)。

不过, 目前现有的理论都是在财政支出总量上考 虑上级政府转移支付的影响，并没有分别考虑不同财 政支出项目。如果对这些财政支出项目分项考虑，财 政自主权对政府支出的影响程度可能会发生变化。 在地方政府支出中, 社会保障支出是重要一块, 包括 社会保险、社会救助、社会优抚和社会福利。根据上 文的分析, 社会保障支出很可能会受到地方政府所获 得的财政拨款多少，即地方财政自主权大小的影响。 不过，尽管转移支付对于政府规模的扩大有正向影响， 但社会保障支出还受到一地经济发展水平、老龄化程 度、公众集聚度、城镇化程度等多种因素的影响（李 胜会, 熊璨, 2016), 且由于社会上需要政府救济的人 群始终存在, 其需要的财政救济不可能随着政府当年 可支配收入大幅上下波动，因此这一财政支出的需求 可以理解成社会的刚性需求。在这种情况下，地方财 政自主权究竟能够对社会保障支出产生多大的影响, 还很难确定。

基于此，本文将财政自主权作为衡量一地财政依 赖中央转移支付程度的指标, 选择了中国 31 个省级 行政单位（不包括港、澳、台)，利用 2009-2018 年 的面板数据, 检验了中国各省财政自主权与社会保障 支出的关系, 并得出一些结论。

\section{3. 变量、模型与数据说明}

\section{1. 变量选择}

\section{1. 1. 被解释变量}

地方政府每年的社会保障支出额可以反映其社 保支出水平，但各地社保支出水平还会受到当地经济 发展水平的影响。由于不同地区经济发展程度不同, 各地区政府在财政实力上、对社保的重视程度上也表 现不同。经济发达地区由于自身财政实力强大、民众 整体素质较高、社保制度完善，可能会更愿意将钱投 入社会保障。因此，不能单纯用社保支出绝对额来表 示。本文用各省的社保支出绝对额占当年 GDP 的比例 （SSR）表示当年的社保支出水平。 


\section{1. 2. 解释变量}

本文试图站在政府官员的角度，考虑政府本身的 因素对其社保支出水平的影响。因此，选取财政自主 权作为解释变量。在此, 本文采取高琳 (2012) 所使 用的指标来度量财政自主权, 即财政自主权=本级一 般预算收入/本级一般预算支出。当然, 严格来说, 一 般预算收入与财政净收入并不相等, 财政净收入应当 $=$ 一般预算收入 + 税收返还 - 上解, 但虽然基于本级净 收入计算得到的财政自主度略高于基于一般预算收 入计算得到的自主度, 两者的相关系数却高达 0.95 (高琳, 2012)。基于此, 本文用一般预算收入替代财 政净收入来衡量财政自主权 (PB)。

\section{1. 3. 控制变量}

老龄化 (AP): 老龄化程度在国际上通常以 65 岁 及以上人口或 60 岁及以上人口占总人口的比重来 衡量。随着近年间经济发展, 我国老年人占比不断上 升, 老龄化程度不断加深。而随着整体死亡率的下降 和平均寿命的延长, 社会上的老年人口增多, 需要社 保供养的人口也就增多; 且经济的发展带来了人们需 求的上升与消费的增加, 需要供养每位老年人的金额 也随之增加。显然, 老龄化对一地的社保支出是有显 著影响的。在此, 本文选取各省当年 65 岁及以上人 口占总人口的比重来衡量其老龄化程度。

对外开放度 (OPEN): 它代表了一个地区经济对外 开放的程度, 本文选取国际上最常见的指标外贸依存 度, 即各省进、出口贸易总额 (因数据限制, 按企业 经营单位所在地区分各省贸易总额）占当年 GDP 的比 例, 作为对外开放度的衡量指标。不过, 这一指标虽 然能够反映一地经济发展水平, 但对社会保障支出的 影响却很难确定。在高开放度的发达地区, 政府往往 有能力聚集更多财政资源提供公共服务, 但经济发达 也意味着政府提供服务的成本较高, 政府不一定会将 大量的钱投入公共服务中。

失业率 (UNEPY): 用失业人口占总劳动人口的比 率来计算这一指标。根据我国规定, 满足条件的失业 者可以享受失业保险待遇, 这是社保支出中的重要一 项。当一地失业率较高时, 政府为保障人民生活、维 护社会稳定，向失业人员发放的保险金总额也会升高。 一地的社保支出水平显然与当地的失业率息息相关。

财政收入 (INC): 政府所取得的财政收入 (包括 本级收入和上级转移支付) 是进行财政支出的前提, 对财政支出水平有很大的影响。因数据限制, 本文用 各省的一般预算收入总额来表示财政收入。

年底人口数 $(\mathrm{POP})$ : 一地人口数量决定了公众对 政府公共服务的需求, 自然也影响了财政支出水平。 考虑到人口总量在一年中不是固定不变的, 本文统一 采用各年年底的人口数量来衡量。

儿童人口占比 (CHILD): 与老年人口相似, 儿童
人口数量增多也会使得政府需要将更多的钱投入针 对儿童的公共服务上, 因此, 社保支出水平也可能会 受到儿童人口占比的影响。在此, 本文用各省当年 14 岁及以上下口占总人口的比重来表示。

\section{2. 数据来源}

本文选取了全国 31 个省级行政单位（港、澳、 台除外) 2009 年 -2018 年的数据。6 5 岁及以上人口占 比由 2009-2018 年《中国统计年鉴》整理所得，其它 变量数据皆来源于国家统计局。同时, 为了保持量纲 的一致性, 对财政收入、年底人口数这两个指标做取 对数处理。

通过对变量的分析可以看出, 各省社保支出水平 的离散程度较小, 但最大值与最小值相差很大。各省 的财政自主权数值不仅离散程度大, 最大值与最小值 之间也有数十倍差距。在几个控制变量中, 除了对外 开放程度的离散程度较大之外, 其余的都较小。其中, 失业率各省的水平集中在 $3 \%$ 左右; 老龄化程度除去部 分省份特别低或特别高之外, 总体在 7\%-9\%左右变动。

表 1 变量定义及描述

\begin{tabular}{c|c|c|c|c|c|c}
\hline 变量类型 & 变量名称 & 变量符号 & 最大值 & 最小值 & 均值 & 标准差 \\
\hline 因变量 & 社保支出占 GDP 的比重 $(\%)$ & $\mathrm{SSR}$ & 18.239 & .652 & 3.34 & 2.084 \\
\hline 自变量 & 财政自主权 $(\%)$ & $\mathrm{PB}$ & 93.137 & 6.4 & 49.329 & 20.28 \\
\hline \multirow{4}{*}{ 控制变量 } & 老龄化 $(\%)$ & $\mathrm{AP}$ & 15.162 & 4.824 & 9.692 & 2.136 \\
\cline { 2 - 7 } & 对外开放度 $(\%)$ & $\mathrm{OPEN}$ & 146.378 & 1.751 & 28.404 & 31.327 \\
\cline { 2 - 7 } & 失业率 $(\%)$ & $\mathrm{UNEPY}$ & 4.5 & 1.2 & 3.349 & .652 \\
\cline { 2 - 7 } & 财政收入 (亿元) & $\operatorname{lnINC}$ & 9.401 & 3.404 & 7.306 & 1.019 \\
\cline { 2 - 7 } & 年底人口数 (万人) & $\mathrm{InPOP}$ & 9.337 & 5.67 & 8.115 & .845 \\
\cline { 2 - 8 } & 儿童人口占比 $(\%)$ & $\mathrm{CHILD}$ & 25.224 & 7.559 & 16.606 & 4.022 \\
\hline \multicolumn{2}{|c|}{ 样本数量 } & \multicolumn{5}{|c|}{310} \\
\hline
\end{tabular}

注：来源于国家统计局

\section{3. 模型构建}

本文采用了静态面板数据模型, 分别对固定效应 和随机效应两种情况进行检验。将模型设定为：

$$
\begin{aligned}
& S S R_{i t}=\beta_{0}+\beta_{1} P B_{i t}+\beta_{2} A P_{i t}+\beta_{3} O P E N_{i t}+ \\
& \beta_{4} U N E P Y_{i t}+\beta_{5} \operatorname{lnINC}_{i t}+\beta_{6} \ln P O P_{i t}+\beta_{7} C_{1 L} H L D_{i t}+ \\
& \gamma_{i}+\delta_{t}+\varepsilon_{i t}
\end{aligned}
$$

其中, $\mathrm{i}$ 代表省份, $\mathrm{t}$ 代表时间, $\beta_{0}$ 表示常数项, $\beta_{n}$ 表示回归系数; $S S R_{i t}$ 表示为第 $\mathrm{i}$ 个省份 $\mathrm{t}$ 年的社 会保障支出额占当年 GDP 的比例, $P B_{i t}$ 表示第 $\mathrm{i}$ 个省 份 $\mathrm{t}$ 年的财政自主权这一解释变量, $A P_{i t} 、 O P E N_{i t}$ 、 $U N E P Y_{i t} 、 \operatorname{lnINC} C_{i t} 、 \ln P O P_{i t} 、 C H I L D_{i t}$ 分别表示第 $\mathrm{i}$ 个 省份 $\mathrm{t}$ 年的老龄化程度、对外开放度、失业率、财政 收入、年底人口数、儿童人口占比这六个控制变量。 $\gamma_{i}$ 和 $\delta_{t}$ 分别表示个体和时间效应, $\varepsilon_{i t}$ 为误差项。 


\section{4. 实证结果和检验}

\section{1. 实证分析结果}

为确保检验结果的有效性, 需要对面板各序列进
行平稳性检验, 平稳性检验最常用的办法就是单位根 检验。本文采用 LLC 检验，发现所有变量原序列平 稳。

表 2 实证分析结果

\begin{tabular}{|c|c|c|c|c|}
\hline \multirow{3}{*}{ 指标 } & \multicolumn{2}{|c|}{ 模型 1} & \multicolumn{2}{|c|}{ 模型2 } \\
\hline & (1) & (2) & (3) & (4) \\
\hline & ssr & ssr & ssr & ssr \\
\hline \multirow[t]{2}{*}{$\mathrm{pb}$} & $-.062 * * *$ & $-.051 * * *$ & $-.068 * * *$ & $-.05 * * *$ \\
\hline & (.014) & $(.015)$ & $(.009)$ & $(.008)$ \\
\hline \multirow[t]{2}{*}{ ap } & & $.127 * *$ & & $.11 * *$ \\
\hline & & $(.055)$ & & $(.046)$ \\
\hline \multirow[t]{2}{*}{ open } & & .01 & & -.006 \\
\hline & & $(.007)$ & & $(.005)$ \\
\hline \multirow[t]{2}{*}{ unepy } & & $.545 * *$ & & .034 \\
\hline & & $(.211)$ & & $(.164)$ \\
\hline \multirow[t]{2}{*}{$\operatorname{loginc}$} & & $.508 * *$ & & $.41 * * *$ \\
\hline & & $(.216)$ & & $(.132)$ \\
\hline \multirow[t]{2}{*}{ logpop } & & $5.101 * *$ & & $-1.323 * * *$ \\
\hline & & (1.992) & & $(.224)$ \\
\hline \multirow[t]{2}{*}{ child } & & .031 & & -.028 \\
\hline & & $(.066)$ & & $(.044)$ \\
\hline \multirow[t]{2}{*}{ _cons } & $6.374 * * *$ & $-43.118 * * *$ & $6.711 * * *$ & $13.015 * * *$ \\
\hline & $(.675)$ & $(16.253)$ & $(.49)$ & $(2.338)$ \\
\hline Observations & 310 & 310 & 310 & 310 \\
\hline Pseudo $\mathrm{R}^{2}$ &.$z$ &.$z$ &.$z$ &.$z$ \\
\hline
\end{tabular}

\section{2. 检验}

用 Hausman 检验来在固定效应与随机效应模型 中进行选择, 依据检验值, 计量模型使用面板数据进 行分析时，应选择固定效应模型（即模型 1)。

表 3 Hausman(1978) specification test

\begin{tabular}{cc}
\hline & Coef. \\
\hline Chi-square test value & 25.856 \\
P-value & .001 \\
\hline
\end{tabular}

根据使用固定效应模型的实证结果来看, 地方政 府的财政自主权对一地社会保障支出有显著的负向 关系。即一地财政自主权越低、当地财政越依赖中央 政府转移支付而非本级税收, 则该地的社会保障支出 会相对较多。具体来看, 一地财政自主权每变动 1 单 位, 该地的社保支出变动 -0.051 。这与前文所说的 “粘纸效应” 相一致。可见, 出于减少税收筹资成本 (税收成本假说) 和尽力在来年获得更多中央拨款的 考虑, 财政自主权低的地方政府愿意支出更多用于社 会保障。

不过，在各省省内，社会保障多数情况下有一个 相对固定的比率，如社保金发放金额在一段时间内总 是固定的, 难以随时进行调整或随着当年省级财政大 幅变化。这一比率主要还是依照当地的经济发展水平、 老龄化程度、失业率、人口数等因素予以确定。虽然 在财政富余的年份, 政府可能在一定程度上提高社会 福利, 但这一幅度总是有限的。一地政府纵然依赖中 央拨款, 每年都有较高意愿支出, 也不会将其大量用
在社会保障这一 “刚性” 需求上。

关于选取的控制变量, 可以看出, 老龄化程度对 社会保障支出有正向影响，但影响程度较小，老龄化 程度每变动 1 单位, 该地的社保支出变动 0.127 。这 可能是因为在我国各省的情况接近, 在现有经济水平 下，各省之间的老龄化水平差别并不是十分明显。这 一点从之前的数据也可以看出。失业率、财政收入和 年底人口数对社保支出的影响也均为正向, 一个省份 失业率越高、人口越多、当年财政收入越多，显然会 将更多的钱投入社保支出。而关于对外开放程度和儿 童人口占比这两个因素, 通过实证检验可以发现, 它 们对于社保支出水平基本都没有影响。

\section{5. 结论与政策建议}

总的来看，地方政府的财政自主权在一定程度上 会影响该地的社会保障支出水平。这是因为: (1)根据 粘纸效应, 中央政府的转移支付会使地方政府支出增 加、财政规模变大。而一地财政自主权越小，说明它 更为依赖中央拨款、会获得更多的转移支付, 因此, 它的财政支出（包括社会保障支出）会相应扩大。(2) 我国现行制度使得地方政府来年能够获得的转移支 付受上年财政支出的影响，这就为地方政府增大开支 提供了动机。尤其对于那些财政自主权低的省份来说, 中央转移支付的多少至关重要。因此, 它会相对更多 地扩大支出以为下一年打算。

不过，从实证结果来看，财政自主权虽然对社会 
保障支出有负向影响, 但这一影响并不是特别大。这 可能与社会保障支出这一项目的性质有关，即社会对 它的 “刚性” 需求使得它很难随政府可支配金额大幅 变动。也就是说, 单从社会保障支出来看, 虽然中央 转移支付的目的在于调节地区差异, 但它却多少受制 于当下的财政分权体制，效果并不是特别大。不过， 中央政府的转移支付包括一般转移支付和专项转移 支付 (因数据限制本文未区分), 因此, 为使财政资金 在社会保障方面更好地发挥作用, 我们可以扩大专项 转移支付比例，关注民生类公共服务，尽力缩小地区 差距; 同时加大对转移支付资金的监管，确保资金能 落到实处，提升人民的生活水平。

\section{REFERENCES}

[1] Lv Bingyang, Moutai. Financial basis for high investment and low consumption $[\mathrm{J}]$. Economic research, 2014, 49 ( 05 ) : 4-18.

[2] Mao J, Lv Bingyang, Ma Guangrong. Transfer payments and government expansion : research based on ' price effect ' [ J ]. Managing the world, 2015 ( 07 ) : 29-41+ 187.

[3] Gao Lin. Decentralization and people ' s livelihood: Empirical research on the impact of fiscal autonomy on public service satisfaction [ $\mathrm{J}$ ].Economic research, 2012,47 ( 07 ) : 86-98.

[4] Li Shenghui, Xiong Guang.Social security expenditure: urban and rural efficiency differences and reasons [ J ].Public management newspaper, 2016,13 ( 03 ) : $135-146+160$.

[5] Fan Ziying, Zhang Jun. The flypaper effect: an explanation of local government scale expansion [ J ].China 's industrial economy, 2010 ( 12 ) : 5-15.

[6] Wang Fang, Peng Chaoran. Public concentration and government audit quality - - analysis based on public choice theory [ $\mathrm{J}]$. Journal of Central South University of Finance and Law, 2015 ( 02 ) : 72-79 + 160.

[7] Fu Wenlin, Shen Kunrong.Equality transfer payments and local fiscal expenditure structure $[\mathrm{J}$ ].Economic research, 2012,47 ( 05 ) : 45-57. 